\section{READERS Insight}

Journal of Research in Psychology

www.readersinsight.net/jrp

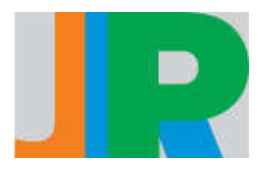

\title{
The Relationship between Employee Motivation towards Green HRM Mediates by Green Employee Empowerment: A Systematic Review and Conceptual Analysis
}

\author{
Nur Aina Binti Mohd Zaki ${ }^{1 *}$, Irmawati Norazman ${ }^{1}$ \\ ${ }^{1}$ School of Human Resource Development and Psychology, Faculty of Social Sciences and Humanities, Universiti Teknologi Malaysia
}

\begin{abstract}
*Corresponding author: nurainazaki@gmail.com
\end{abstract}
ARTICLE INFORMATION

Received: $4^{\text {th }}$-May-2019

Revised: $12^{\text {th }}-$ July-2019

Accepted: $1^{\text {st }}$-Aug-2019

Keywords: Motivation, green human resources management, green employee empowerment.

\section{INTRODUCTION}

Nowadays, organization are getting more concerned and aware about the environmental issues and sustainable development that occurs in the developing countries (Masri \& Jaaron, 2017). According to Siyambalapitiya, Zhang, \& Liu (2018), the emerging environmental issues have compelled public and private organizations to find the ways to solve the environmental issues and focusing towards the sustainable future. One way organizations can contribute to sustainable environment is by practicing the newly emerging concept of "green human resource management” (GHRM) (Ren, Tang, \& Jackson, 2018). GHRM is a green managerial practice which aligns organizational management practices with sustainable environment (Siyambalapitiya et al., 2018). Employees in the organization must be encouraged, empowered and eco-conscious to ensure that employees is moving towards green organizational functions (Tariq, Ali, \& Ahmad, 2016).

Organizational green functions are extended to human resource management practices such as human resource planning, job design, job analysis, recruitment and selection, training and development, performance evaluation, reward management, discipline management, safety and health management and employee relations, etc. (Arulrajah, 2015). Organizations may involve employee in terms of encourage them in decision making and problem solving to give them empowerment in their job task. Organization that empowered their employee and assigned green task to them, its will falls under termed 'Green Employee Empowerment” (Tariq et al., 2016).

This conceptual literature review study is focused on the employee motivation towards green HRM. According to the Sherif et al.,(2014) , its is important to improve in terms of the employee job satisfaction in order to achieve organization efficiency towards maintaining motivation level of the employees. Referring to the environmental responsibilities to the employees, by getting positive feedback from the supervisor or managers actually its helps to boost employees knowledge, skills and abilities and at the same time its help to increase motivation of the employees (Tan et al., 2019). This conceptual study also focus on the green employee empowerment as a mediating effect towards green HRM practice.

\section{LITERATURE REVIEW}

Motivation is important for the people either to stay or work hard in the certain position that been appointed to them. How an organizational based motivation relates to best human resource practices? This can be explained through manager who need to fully understand their subordinates job scope, to know how to tackle their motivation and drive them to perform well in the organization. As an employee, it is important to know what factors are needed improve in 
their daily job task and know how to achieve manager expectation towards them. This is important because employee motivation is related with their daily job, their surroundings in the workplace. For example, if employee is working under stressful condition, being pushed to limits every single day it affects their emotional and performance in the workplace. Employees may increase their motivational level by empowering them to achieve their goals and become motivated employees leading to organization profitability. The degree of employee motivation may affect their internal satisfaction and the employee feels that they are being empowered and motivated to achieve personal and organization goals (Tariq et al., 2016). In addition, the learning of the environmental friendly behaviours have impact on other similar activities and the implementation of GHRM practices may improve employee lifestyle (Fatima et al., 2017).

Basically, the process of learning towards environmentally friendly behaviours requires continuous learning from initiative of employee itself with the help of organization support to drive them to achieve towards sustainable development. Employees motivation could be identified towards organization green culture and work values in order to improve employee performance, job satisfaction and to develop committed attitude towards task given (Khaled Aladwan,Ramudu Bhanugopan, 2015). Organization role to develop employees green abilities, motivate by using green rewards to the employees and giving the green opportunities towards employees to ensure employee may increase their productivity, organization performance and profit, reduce waste (Fatima et al., 2017). In addition, to include people management to participate in the concept of GHRM, previous researcher had used ability-motivation-opportunity theory (AMO) to demonstrate the effect of HR practices in the organization outcomes (Tariq et al., 2016). Basically, AMO theory had further explained that individual performance can be determined in terms of their ability, motivation and opportunity to perform.

Green Human Resources Management (GHRM) can be essential tools for the organization to implement sustainability in through both traditional HR practices, policies, technique with environmental goals and towards strategic dimensions for HR management (Gholami, Rezaei, Zameri, \& Saman, 2016). Basically, in this conceptual study its focus on many ways to motivate employees in the green practices within the organization. Referring to the (Renwick, Douglas, 2008) green practice require; employing talented staff, design job for employee involvement and development, training of GHR practices, control and evaluation on GHR practices and reward systems linked with the environmental performance. Besides that, previous study of GHRM (Douglas W.S. Renwick \& Maguire, 2013), had using AMO theory to monitor employees performance outcomes through these three core components. Basically, it is the ability to focus on attracting develop high performing employees to ensure its match with the organization goals. In terms of motivation and commitment it consists of the motivation towards monetary and non-monetary rewards and effective performance management. Under opportunity it is involve with the problem-solving activities, knowledge sharing through the programmes that can be conducted to the employees (Douglas W.S. Renwick \& Maguire, 2013). Those study had using AMO theory as based to relate with GHRM. However, from the study, there are limitation studies that focus on AMO theory with GHRM practice at the workplace.

This conceptual study, had use employee empowerment to strengthen organization outcome to ensure the employees are motivated to achieve green goals efficiently and effectively (Tariq et al., 2016). Green employee empowerment had become potential mediator to study about employees' motivational levels towards green practices in the organization. Employee empowerment is a practice that related with the job task performed and job satisfaction.

\section{METHODOLOGY}

We have focused on the conceptual exploration of relationship between employee motivation and GHRM. The study is conducted through systematic literature review and conceptual analysis. Further, the studies had been separated into four steps: first, we developed a database by using conceptual and systematic literature and to identify the relevant literature that relate with the Employee motivation-GHRM that studies been published in the academic journals. Secondly, constant process between the theoretical and empirical that can develop a template to analyse the articles. Third, based on the articles that been retrieved, the content analysis is been used to extract descriptive and qualitative conceptual data. Finally, the results of the findings were interpreted meaningfully.

The first step under development of the database to find suitable journal that relate with the studies. The process that had gone through to obtain previous published journal by using Journal online database. We had use Boolean search to find the relevant journal according to the topic. Systematic literature review summary is prepared as shown in table for the relevancy of the mediating effect of green employee empowerment towards employee motivation and GHRM practices. Based on the study, green employee empowerment cover wide range of activities and the content of the task, have a relation with the job satisfaction that employee will get (Pelit, 2011).

The initial step comprised the identification of the relevant research. To capture previously published research in the studies had conducted a Boolean search of these, with the combining one of several 'employee motivation-terms' and or 'GHRM-terms' with 'Green Employee Empowerment', in the title, abstract or subject terminology of peer-reviewed journals, and find all the possible combinations terms are repeatedly conducted Online Journal database had continuously updated the database to ensure the studies are getting updated key terms. In addition, overall search process had obtained initial database of 473 articles.

Table 1. Search findings from Database

\begin{tabular}{lll}
\hline Databases & Language & Returns \\
\hline Emerald Insight & English & 223 article \\
Science Direct & English & 133 article \\
SpringerLink Journal & English & 117 article \\
\hline
\end{tabular}

Furthermore, through initial database that found 473 articles based on the terms given, the studies had narrow down the journal to 30 journals based on employee motivation and green HRM. Next, the journal had been screened and reviews by using inclusion and exclusion criteria that related with this study. The criteria are as below:

Inclusion criteria:

1. Type of study: systematic review, descriptive study and indepth analysis

2. Target person/sample: Type of respondents that relate with employee in workplace and students in university

3. Outcomes: Any studies that investigate the relationship of motivation towards green HRM

Exclusion criteria:

1. Type of study: meta-analysis study, student's thesis, conference paper and governmental report

2. Research focus: Any studies that not related with green HRM 
After the initial step of creating the database, content analysis was done based on the relevant information what was collected from 30 articles and is related with bibliographical data, research process and research content. Further, descriptive data in template to show the constant information from the journals. The final template was used for analysis are categories with title, authors, year of publication, type of journal, research objectives, key finding, limitation and future research recommendation.

\section{RESULT AND DISCUSSION}

\section{Development of Green HRM}

Based on the systematic review of employee motivation and Green HRM had been analysed. Studies had found the trends had been changing over time and the themes has intersection of employee motivation and Green HRM. Its show that the researcher's interest towards green HRM in increasing towards 2010s. this is because, the concept is introduced to the organizations and they have started to studies in this area. Therefore, in 2010s topic green HRM had been started to influence to maintain environmental sustainability. Referring to the fig 1, its shows that green HRM play important roles in current study.

\section{GREEN HRM}

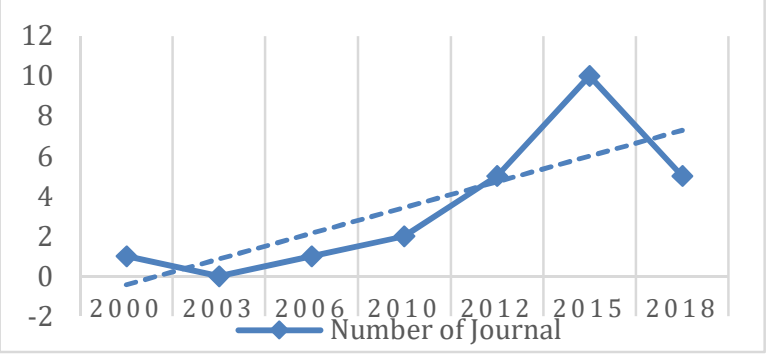

Fig.1. Publications years for GHRM

\section{Relating Employee Motivation with Green HRM}

Employee motivation is important for employers to take care in order to have positive employee at the workplace. There are two type of motivation which are intrinsic and extrinsic motivation. Intrinsic motivation occurs when employee is motivated to perform green behaviour towards their own satisfaction. Extrinsic motivation occurs when employees motivated to do something to get the rewards given by the organization. These two are different type of motivation that employees usually faced. As an employer they are play important role to provide morale support to their employees to ensure that employee is well motivated when they are coming to work.

The relationship of employee motivation towards GHRM are GHRM is the new HRM practice that been implement to the employees, however how the employers want to execute their idea to their employee and its can be solve by giving green training and development to them. Basically, when employers are introducing something new to the employees, they need to perform induction program or awareness program towards environmental sustainability. Those are important for the employee to ensure that they are fully understand and have a knowledge about the program want to implement in their organization. When the organization successful implement GHRM, employee motivation towards their green job task is increase because employee is shared same set of values and engagement with others. Besides that, when employee is motivated, there are likely for their performance to be improved. This is because, employee motivation and job performance are inter related with each other. Job performance is a benchmark for employer to measure the effectiveness and efficiency of the employee towards their jobs. For example, employer is giving certain project to accomplish within stipulated times and employee are complete it is using short period only. This can show that employee is well motivated and able to make environmental strategies successful. Employees also motivated if employers implement pay and reward system to the employees that contribute and using environmental practices in their daily job task. Employers should reward those who shows their potential to grow in the green organization.

\section{Abilities-Motivation-Opportunity Theory}

Abilities-Motivation-Opportunity Theory is commonly related with the impact of HRM practices on the organization performance. Under AMO theory, HRM practice can implement by using green abilities to attract and develop talented staff. For example, organization will briefly explain about vision mission towards green organization performance, throughout the process of implementation employer may observe who are talented staff that interested to expand more knowledge in the green performance. Attracting staff also can be accomplish through the green recruitment and selection. Recruitment and selection are the entry process of HRM and organization may include all the organization environmental practice, green organization mission and vision so that candidate that apply they are fully aware that this organization is practicing green organization (Gholami, Rezaei, Zameri, \& Saman, 2016).

Furthermore, motivating green employees can be accomplish by using performance management and performance appraisal. These two components should be align with the green organization standards that been practiced in the organization. Employee should aware with the core components in their position, so that they are able to fulfil it towards organization performance. Green performance area is the environmental responsibilities and communication about environmental concerns and policy. Performance appraisal is usually accomplished by line manager towards their subordinate's quarterly basis or yearly basis. It is important for employee to know their current performance standard is it align with the organization expectations or not (Douglas W.S. Renwick \& Maguire, 2013)

In addition, AMO theory also have green opportunities that given to the employees. Opportunity given to the employees by sharing to them their career path grows in the green organization. Employees has a right to know what career grow that may offer or given to them if they are showing good performance in the organization. For example, as an HR staff they are starting with the HR Assistant continue with HR Officer, HR Executive and HR Manager. Those are career path goals that may achieve by HR staff if their work is beyond expectations and those opportunity are for them.

AMO theory had given impact towards green organization because three components had play important roles towards the implementation of the green organization. For certain organization to successfully implement certain practices they need to have support from the top management, managers to execute the information to their subordinates. This is because, managers are more expert and well known with their subordinate's daily job tasks, core components and 
others. Managers need to implement green culture to ensure it is aligned with the organization performance (Tan et al., 2019).

Referring to the previous researcher (Tariq et al., 2016), the study had shown green employee empowerment giving impact towards employee motivation and green HRM. Employee empowerment is a trust that given by the organization towards the employees. For example, manager can voice their opinion about the implementation of the green culture in the organization, to know which part are suitable to change with their current culture. When feedback had been given, top management are aware and hear and respond the feedback accordingly. This is when empowered is given to the manager because top management listen and change according to the feedback received from them. Empowered also means giving opportunity for the employees to voice out and decide which part is not suitable with the green culture implementation.

Furthermore, to know the effectiveness of the certain changes, top management need to know what the outcome and feedback from the end user is. Feedback may acquire from the interview session from manager to their subordinates, feedback form given to the employees, observation towards employee's performance and others. Those elements are play important roles to ensure that employees are fully accept the changes in the green environmental culture.

In addition, green employee empowerment had related with the employee motivation and green HRM because when employee are feels that they are been appreciated because their feedback had been listened, they are motivation to perform their daily job task towards green HRM functions that been implement to the organization.

\section{CONCLUSION}

GHRM is basically a core concept for the organization and giving effect towards to maintain environmental sustainability. Green HRM also shown as effective effect ways to encourage employees to be successful in the environmental aspects (Verlag, 2011). In this conceptual study, as we can see that employee that have high motivation will be likely to presume their task towards the organizations needs. Since the organization had implemented green HRM practices to their employees, as an employer they need to give fully motivation by using Ability-Motivation-Opportunity Theory. Those 3 core elements is highly related with the employees successfulness in the organization.

Furthermore, in order organization to maintain with Green HRM practices, they need play important roles to ensure that employees are following green practice in their daily job task. This can be done by appointed a person to monitor everything that related with the green practices. It is such a good move for the organization when they are practicing green HRM meaning they are supported to maintain environmental sustainability.

In addition, employee motivation and green HRM concept had use green employee empowerment as a mediator in this study. Green employee empowerment roles in this study to identify and explain the process underlies of the relationship between employee motivation and green $\operatorname{HRM(Khaled~Aladwan,Ramudu~Bhanugopan,~2015).~The~}$ practices of the green employee empowerment basically to giving voice to the employees and allowed them to involve in terms of decision making and problem solving of certain issues in the organization. Based on the conceptual study, when the components of green HRM is fulfilled, its is empowered employees to become more motivated to complete their task in the organization. Throughout the green HR practices in their daily job task, it will be automatically implemented green employee empowerment to incorporate with the green management for their daily functions. After integrating and aligning the data from the relevant literature, the findings showed that there exists a potential mediating effect of green employee empowerment on employee motivational levels for pursuing GHR practices.

Furthermore, future research could improve this study by finding related factors that had impact towards green HRM and its could enhance study for the green HRM.

\section{REFERENCES}

Arulrajah, A. A. (2015). Green Human Resource Management Practices : A Review Literature Review on Green HRM Practices, 5(1), 1-16.

Douglas W.S. Renwick, T. R., \& Maguire, S. (2013). Green Human Resource Management: A Review and, 44(January), 0-35.

Fatima, S., Ragas, P., Mae, F., Tantay, A., Joyce, L., Chua, C., ... Tantay, A (2017). Green lifestyle moderates GHRM's impact on job performance. https://doi.org/10.1108/IJPPM-04-2016-0076

Gholami, H., Rezaei, G., Zameri, M., \& Saman, M. (2016). State-of-the-art Green HRM System : sustainability in the sports center in Malaysia using a multi-methods approach and opportunities for future research, 124. https://doi.org/10.1016/j.jclepro.2016.02.105

Khaled Aladwan,Ramudu Bhanugopan, B. D. (2015). The effects of human resource management practices on employees ' organisational commitment. International Journal of Organizational Analysis, 23(3), 472-492. https://doi.org/10.1108/IJOA-11-2014-0822

Masri, H. A., \& Jaaron, A. A. M. (2017). Assessing green human resources management practices in Palestinian manufacturing context: An empirical study. Journal of Cleaner Production, 143, 474-489. https://doi.org/10.1016/j.jclepro.2016.12.087

Pelit, E. (2011). The effects of employee empowerment on employee job satisfaction A study on hotels in Turkey, 23(6), 784-802. https://doi.org/10.1108/09596111111153475

Ren, S., Tang, G., \& Jackson, S. E. (2018). Green human resource management research in emergence: A review and future directions, 769-803. https://doi.org/10.1007/s10490-017-9532-1

Renwick, Douglas, T. R. (2008). Green HRM : A review , process model , and research agenda, 44(0).

Sherif, M. Z. M., Nimran, P. U., Prasetya, A., Sos, S., Si, M., \& Ph, D. (2014) The Role of Motivation in Human Resources Management: The Importance of Motivation Factors among Future Business Professionals in Libya, 16(8), 27-36.

Siyambalapitiya, J., Zhang, X., \& Liu, X. (2018). Green human resource management: A proposed model in the context of Sri Lanka's tourism industry. Journal of Cleaner Production, 201(02), 542-555. https://doi.org/10.1016/j.jclepro.2018.07.305

Tan, N., Tučková, Z., José, C., Jabbour, C., Bata, T., \& Republic, C. (2019) Greening the hospitality industry: How do green human resource management practices influence organizational citizenship behavior in hotels? A mixed-methods study. Tourism Management, 72(August 2018), 386-399. https://doi.org/10.1016/j.tourman.2018.12.008

Tariq, S., Ali, F., \& Ahmad, M. S. (2016). Green employee empowerment : a systematic literature review on state-of-art in green human resource management. Quality \& Quantity, 237-269. https://doi.org/10.1007/s11135-014-0146-0

Verlag, R. H. (2011). www.econstor.eu. https://doi.org/10.1688/1862-0000 